\title{
Two Interferons Alpha Influence Each Other During Their Interaction With the Extracellular Domain of Human Type I Interferon Receptor Subunit 2
}

\author{
Hana Schmeisser , $^{*}$, Inna Gorshkova§, Patrick H. Brown§, Peter Kontsek ${ }^{\|}$, Peter Schuck§, \\ and Kathryn C. Zoon $¥$
}

$\ddagger$ NIH, NIAID, Bethesda, MD, USA

$\S N I H, N I B I B$, Bethesda, MD, USA

|| Institute of Neuroimmunology, SAS, Bratislava, Slovak Republic

\section{Abstract}

The interaction between two human interferons alpha (IFN- $\alpha$ s) and the extracellular (EC) domain of human type I IFN receptor subunit 2 (IFNAR2) was analyzed. Previous experiments using Daudi cells showed that IFN- $\alpha 21 \mathrm{~b}$ and some IFN- $\alpha$ hybrids (made from IFN- $\alpha 2 \mathrm{c}$ and $21 \mathrm{~b}$ ) competed poorly for the IFN- $\alpha 2 \mathrm{~b}$ binding site. This study examined the causes of the poor competition between these IFN- $\alpha$ s. IFN- $\alpha 2 c$ and the IFN hybrid CM3 $\{$ IFN- $\alpha 21 b(1-75)(81-95) / I F N-\alpha 2 c(76-80)(96-166)$, Y86K \} were selected for this study based on their cell binding and biological properties. Competitive binding ELISA, native electrophoresis followed by Western blot, electrospray ionization mass spectrometry (ESI-MS), surface plasmon resonance biosensor (SPR) analysis, as well as neutralization of antiproliferative activities on Daudi cells in the presence of soluble IFNAR2-EC show evidence that each of the described IFN- $\alpha$ subtypes affected the binding of the other IFN- $\alpha$ to IFNAR2-EC by affecting the stability of the complex, i.e. dissociation of the complex. Moreover, native electrophoresis with different IFNAR2-EC mutants showed that IFN- $\alpha 2 \mathrm{c}$ and CM3 utilize different amino acids in the binding domain of IFNAR2-EC. In addition to that, analytical ultracentrifugation (AUC) revealed differences in the oligomeric state of the two studied interferons. Our results demonstrated that two individual IFN- $\alpha$ s interact differentially with IFNAR2-EC and influence each other during this interaction. This study contributes to the understanding of the mutual interaction between multiple IFN- $\alpha$ subtypes during the competition for binding to the receptor.

In mammals, the type I IFNs are grouped into five major classes: $\alpha, \beta, \varepsilon, \kappa, \omega(1,2,3)$. They are induced in all nucleated cells in response to viral and bacterial infections, natural and synthetic double-stranded RNA, mitogens, protozoa and certain cytokines $(3,4)$.

Human IFN- $\alpha$ is represented by a group of related subtypes, encoded by a multigene family comprising 14 non-allelic genes. At the protein level, there is 75\%-99\% identity in the primary structure of human IFN- $\alpha$ species $(5,6,7)$. Individual subtypes show quantitatively distinct spectra of antiviral, antiproliferative and immunomodulatory activities $(8,9,10,11)$. The existence of the numerous subtypes of IFN- $\alpha$ may provide a fine mechanism of regulating the biological effect of IFN.

* To whom correspondence should be addressed. NIH/NIAID, HFM 8001, 50 Center Drive, building 50, room 5515, Bethesda, MD 20892, Telephone: 301-402-5369, Fax: 301-594-6496, E-mail: hschmeisser@niaid.nih.gov. 
The type I IFNs bind with distinct affinities to the common type I IFN receptor complex (IFNAR), expressed on the surface of target cells in low numbers (100-5000 molecules/cell) $(12,13,14)$. Functional human IFNAR is a heterodimeric complex composed of two transmembrane polypeptide chains, IFNAR1 and IRNAR2, with distinct complementary functions, which associate to form a heterodimer upon IFN-binding $(7,15)$. The IFNAR1, with a molecular weight of $110-130 \mathrm{kD}$, has a very low affinity for IFN- $\alpha \mathrm{S}\left(\mathrm{K}_{\mathrm{D}} \sim 10^{-6} \mathrm{M}\right)$. IFNAR1 alone binds only one species of IFN- $\alpha(\alpha 8)$, but is required for signaling by all type I IFNs (16). The second component, IFNAR2 has a molecular weight of $95 \mathrm{kD}$. The protein alone displays a relatively high affinity for binding of IFNs $\left(\mathrm{Kd} \sim 10^{-9} \mathrm{M}\right)$ and is the major ligandbinding receptor subunit (13). The dimerization of IFNAR2 with IFNAR1 results in a fully functional receptor and its binding affinity increases by approximately 100 -fold $\left(\mathrm{Kd} \sim 10^{-11}\right.$ M).

Previously, the antiproliferative and competitive binding activities of 20 purified components of human lymphoblastoid IFN were compared with that of recombinant human IFN- $\alpha 2 b$ on Daudi and AU937 cells (12). Moreover, differences between IFN hybrid molecules (derived from IFN- $\alpha 2 \mathrm{c}$ and IFN- $\alpha 21 \mathrm{~b}$ ) in competition for receptor binding site were reported (17).

Most recent studies were focused on detailed mapping of interferon receptor binding site (18, $19,20,21,22,23,24)$. However, little is known about the mutual interaction among different IFN- $\alpha$ subtypes during the process of binding to the receptor.

The aim of this study was to understand the interaction between two distinct IFN- $\alpha$ s and IFNAR2-EC. To this end, we applied several different assays (ELISA, SPR, native electrophoresis followed by Western blot, ESI-MS, AUC), each of which highlighting select aspects of the interactions. Taken together, a complex picture of the interaction emerged with features previously unrecognized. Although the detailed mode of interaction in the membrane is still unclear, our study revealed evidence for differences in IFN/IFN/receptor complex stability e.g. the mutual influence between IFN- $\alpha$ subtypes during their binding to IFNAR2EC. Moreover, IFNAR2-EC mutants showed that the studied IFN- $\alpha$ s bind to the IFNAR2-EC with distinct binding centers.

\section{Experimental Procedures}

\section{Cell Lines}

Human Daudi cells were a gift from Dr. P. Grimley (Department of Pathology, Uniformed Services University of the Health Sciences, Bethesda, MD). Bovine kidney MDBK cells were obtained from the American Type Cell Culture Collection (ATCC, Manassas, VA). Daudi and MDBK cells were cultured in RPMI 1640 medium (GIBCO, Invitrogen Corp., Grand Island, $\mathrm{NY}$ ) with $10 \%$ fetal bovine serum (GIBCO), $2 \mathrm{mM}$ glutamine (GIBCO) and $0.2 \%$ gentamicin (Cambrex Bio Science, Walkersville, Inc., MD). Cells were incubated at $37^{\circ} \mathrm{C}$ in a humidified atmosphere containing $5 \% \mathrm{CO}_{2}$. All cells were determined to be free of mycoplasma.

\section{Interferons}

Recombinant IFN- $\alpha 2 c$, IFN- $\alpha 2 c-6$-histidine-tag, and hybrids IFN- $\alpha 21 b$ (1-75) (82-95)/IFNa2c (76-81) (96-166) with Y86K (designated CM3), and CM3-6-histidine-tag were generated as previously described $(17,24)$. Specific activities of IFNs on MDBK were $4.9 \times 10^{8}$ (IFN$\alpha 2 \mathrm{c}$ ), $3.2 \times 10^{8}$ (IFN- $\alpha 2 \mathrm{c}-6$-histidine-tag), $2.8 \times 10^{8}$ (CM3), and 3.5 $\times 10^{8}$ (CM3-6-histidine-tag) $\mathrm{IU} / \mathrm{mg}$ protein. Preparation and purification of IFNs was described previously $(17,24)$. Ellman assays (25) under native and denaturating conditions were performed to assess free cysteine residues. The purity of the IFNs was evaluated by SDS-PAGE under reducing and non-reducing conditions followed by staining with Coomassie R-250 (Pierce, Rockford, IL). Samples were 
incubated for 5 minutes at $90^{\circ} \mathrm{C}$ with or without NuPAGE sample reducing agent (Invitrogen, Carlsbad, CA) and resolved on 10-20\% tris-glycine gel (Invitrogen). Novex Tris-Glycine SDS Running Buffer (Invitrogen) and Novex Tris-Glycine SDS Sample buffer (Invitrogen) were used for SDS-PAGE. Protein in IFN samples were evaluated using the Bradford protein quantification assay (Pierce). The order of the $\mathrm{N}$-terminal amino acids was confirmed by protein sequencing.

\section{Soluble IFNAR2-EC}

The EC domain of human type I IFN receptor subunit 2 (IFNAR2-EC) and IFNAR2-EC mutants (I47A, M48V and I105A) were a generous gift from Dr. G. Schreiber. Expression and purification have been described by Piehler (21).

\section{Monoclonal antibodies}

The following murine monoclonal antibodies were used: mAb N27 (epitope 43-53) against IFN- $\alpha 2 c$ (26), mAb NK2 (epitope 112-132) against human leukocyte IFN (27), mAb 1-36 (epitope 63-85) against human IFN- $\alpha 1$ (28), mAb 4F2 (epitope 113-149) against consensus IFN- $\alpha$ (9) and mAb III/21 against a synthetic fragment 151-165 of IFN- $\alpha 1$ (29). All antibodies have IFN-neutralizing activity except mAb III/21, and were used as hybridoma culture supernatants containing respective antibodies at concentrations of 5-10 $\mu \mathrm{g} / \mathrm{ml}$. MAb 46.10 against soluble IFNAR2-EC (13) was kindly provided by Dr. D. Novick. Monoclonal antibody NK2 was obtained from Lonza Biologics PLC Slough, Berkshire, UK, mAb III-21 was a generous gift of Dr. H. Arnheiter (National Institute of Neurological Disorders and Stroke, NINDS) and mAb 4F2 was kindly provided by Dr. E. Swanson (Amgen, Thousand Oaks, CA).

\section{Solid phase IFN ELISA and sandwich IFNAR2-EC ELISA I}

In solid phase IFN ELISA (used as control), Immulon 2HB microtitration plates (Dynatech Laboratories Inc., Chantilly, VA) were directly coated overnight at $4^{\circ} \mathrm{C}$ with IFNs $(3 \mu \mathrm{g} / \mathrm{ml}$, $50 \mu \mathrm{l} /$ well in PBS), and then specific mAbs (C- or N- terminal) were added. In the sandwich IFNAR2-EC ELISA I, Immulon 2HB polystyrene microtitration plates were coated overnight at $4{ }^{\circ} \mathrm{C}$ with IFNAR2-EC ( $3 \mu \mathrm{g} / \mathrm{ml}, 50 \mu \mathrm{l} /$ well in phosphate-buffer saline - PBS, $\mathrm{pH}$ 7.2); then IFNs $(10 \mu \mathrm{g} / \mathrm{ml}, 50 \mu \mathrm{l} /$ well in PBS) were added, followed by specific anti-IFN (C- or Nterminal) mAbs. The next step was repeated in all our ELISA experiments: After incubation for 1 hour at $37^{\circ} \mathrm{C}$, the plates were washed, and secondary peroxidase-labeled goat anti-mouse $\operatorname{IgG}(\mathrm{H}+\mathrm{L})$ antibodies (diluted 1:1000) were added, followed by incubation for 1 hour at $37^{\circ}$ C. Positive reactions were visualized by the addition of 2,2'-azino-di-3-ethylbenzthiazoline-6sulfonate (ABTS) peroxidase substrate solution \{Protein Detector ELISA Kit (HRP, ABTS System) (Kirkegaard and Perry Laboratories, Gaithersburg, MD) \}. Absorbance at $405 \mathrm{~nm}$ was measured in an ELISA microplate reader. Measurements were performed at least three times, and the results were consistent with data from representative experiments shown in the figures.

\section{Sandwich IFNAR2-EC ELISA II}

The sandwich IFNAR2-EC ELISA II was used to titrate the binding of the designated IFNs to the IFNAR2-EC. Immulon $2 \mathrm{HB}$ polystyrene microtitration plates were coated overnight at $4^{\circ}$ $\mathrm{C}$ with a concentration of IFNAR2-EC ( $3 \mu \mathrm{g} / \mathrm{ml}, 50 \mu \mathrm{l} / \mathrm{well}$ in PBS). Interferons IFN- $\alpha 2 \mathrm{c}-6$ histidine-tag (1-18 $\mu \mathrm{g} / \mathrm{ml})$ or CM3-6-histidine-tag $(10-180 \mu \mathrm{g} / \mathrm{ml})$ were then added at a volume of $50 \mu \mathrm{l} /$ well in PBS, followed by the specific anti-IFN mAbs. After incubation at different time intervals $\left(1,2,3\right.$ and 4 hours) at $37^{\circ} \mathrm{C}$, the plates were washed, and secondary antibodies were added, followed by incubation for 1 hour at $37^{\circ} \mathrm{C}$. Positive reactions were visualized and absorbance was measured as described above. 


\section{Competitive sandwich IFNAR2-EC ELISA}

Immulon $2 \mathrm{HB}$ Polystyrene microtitration plates were coated overnight at $4{ }^{\circ} \mathrm{C}$ with a concentration of IFNAR2-EC ( $3 \mu \mathrm{g} / \mathrm{ml}, 50 \mu \mathrm{l} /$ well in PBS). Then, IFN- $\alpha 2 \mathrm{c}-6$-histidine-tag or CM3-6-histidine-tag were added at a concentration of 15 or $150 \mu \mathrm{g} / \mathrm{ml}$, respectively, (50 $\mu \mathrm{l} /$ well in PBS). After incubation for 3 hours at $37^{\circ} \mathrm{C}$, the plates were washed and the second IFN (IFN- $\alpha 2 \mathrm{c}-6$-histidine-tag, $1-15 \mu \mathrm{g} / \mathrm{ml}$ or CM3-6-histidine-tag, 10-150 $\mu \mathrm{g} / \mathrm{ml}$ ) in PBS $50 \mu \mathrm{l} /$ well was added. After incubation for 1 hour at $37^{\circ} \mathrm{C}$, the plates were washed. A specific $\mathrm{mAb}$ targeted against the second IFN was added, and incubated for 1 hour at $37^{\circ} \mathrm{C}$. Plates were washed, and secondary antibodies were added, followed by incubation for 1 hour at $37^{\circ} \mathrm{C}$. Positive reactions were visualized and absorbance was measured as described above.

\section{Competitive binding study by biosensor analysis}

SPR experiments were performed with a BIAcore 3000 optical biosensor at $25^{\circ} \mathrm{C}$ in the running buffer HBS (10 mM HEPES, pH 7.4, 150 mM NaCl, 1 mM EDTA, 0.005\% P20). CM5 Sensor chips with a carboxymethylated dextran matrix, EDC, NHS and P20 surfactant were obtained from BIACORE AB (Piscataway NJ). Proteins (IFNAR2-EC, IFN2- $\alpha 2 \mathrm{c}$ or CM3) were covalently attached to the chip surface by amino coupling. At a flow rate of $10 \mu \mathrm{L} / \mathrm{min}, 70$ $\mu \mathrm{L}$ of the mixture of freshly thawed EDC and NHS was employed to activate the surface, followed by the injection of the corresponding protein that was diluted into $10 \mathrm{mM} \mathrm{NaOAc}$ buffer $\mathrm{pH} 4.5$ at a concentration of $30-35 \mu \mathrm{g} / \mathrm{mL}$. The protein injection was stopped when the desired immobilization level was reached ( 1250, 2700 and 5900 RU for IFNAR2-EC, IFN$\alpha 2 \mathrm{c}$ and CM3, respectively). Then, each surface was deactivated by $70 \mu \mathrm{L}$ of $1 \mathrm{M}$ ethylenediamine $\mathrm{pH} 8.5$ and washed thoroughly with HBS. The reference surfaces, which were treated with NHS/EDC and ethylenediamine, were generated on each sensor chip.

Approximately $50 \%$ of the pre-concentrated IFN- $\alpha 2 \mathrm{c}$ (or CM3) became irreversibly attached to the chip surface; typically $\sim 25 \%$ of the immobilized IFN- $\alpha 2 \mathrm{c}$ ( $30 \%$ of CM3) was active and could reproducibly bind IFNAR2-EC in HBS within at least a day. Approximately $70 \%$ of the pre-concentrated IFNAR2-EC became irreversibly attached to the chip surface; typically $\sim 35 \%-50 \%$ of the bound IFNAR2-EC was active in binding of IFN- $\alpha 2 \mathrm{c}$ or CM3. The behavior of the immobilized proteins was in overall agreement with previously published data for IFN$\alpha 2 c$ and IFNAR2-EC interaction, which was studied by RIfS optical biosensing $(21,22)$.

To detect the interaction in HBS buffer, a sample volume of $20 \mu \mathrm{L}$ of IFNAR2-EC, IFN- $\alpha 2 \mathrm{c}$, and CM3, separate or mixed, was injected at a flow rate of $5 \mu \mathrm{L} / \mathrm{min}$ onto the surface with the counterpart immobilized. Then, the surface-bound complex was allowed to dissociate. In some experiments, soluble IFN- $\alpha 2 \mathrm{c}$ or CM3 was added in the dissociation phase allowing it to interact with the surface-bound receptor and the receptor-interferon complex (see details in the legends to Figures). In the latter experiments, in order to control for the absence of oligomers or aggregates in the interferon samples, experiments were conducted with and without an additional FPLC purification step prior to the SPR studies, without significant differences in the observed binding traces. The response from the reference surface was subtracted from that of each of the experimental surfaces to correct for refractive index changes, matrix effects, nonspecific binding, injection noise, and baseline drift.

For a quantitative characterization and comparison of binding curves, initially the model of a simple bimolecular reaction was fitted to the data to estimate apparent kinetic and equilibrium constants (30). However, as outlined in the Results section, a more complex binding mode is present, and as a consequence we do not believe these apparent binding constants reflect the molecular properties. 


\section{Self-association state of IFNs in solution by analytical ultracentrifugation}

Solutions of IFNs were prepared by serial dilution of a concentrated stock that had been passed through a size exclusion column (TSK-GEL) to $0.8,0.4$, and $0.1 \mathrm{mg} / \mathrm{mL}$ for IFN- $\alpha 2 \mathrm{c}$ and 1.0 , 0.5 , and $0.1 \mathrm{mg} / \mathrm{mL}$ for CM3 using $10 \mathrm{mM}$ HEPES ( $\mathrm{pH} 7.1), 150 \mathrm{mM} \mathrm{NaCl}$ ) as column running buffer. Three hundred ninety $\mu \mathrm{L}$ of these solutions were loaded into double-sector charcoalfilled epon centerpieces with SEC column running buffer as the reference solution. Samples were spun in a Optima XLI (Beckman Coulter) analytical ultracentrifuge at $20 \mathrm{C}$ and 50, 000 rpm while the time- and radial- dependence of the resulting concentration gradient was acquired using absorbance detection. Data analysis was performed utilizing the software Sedfit (vs. 10.01; www.analyticalultracentrifugation.com) to obtain sedimentation coefficient distributions $\mathrm{c}(\mathrm{s})$ with root-mean-squared deviations (rmsd) of all fits below 0.007. Integrated weight-average sedimentation coefficients were uncorrected for buffer density or viscosity or for the partial specific volume of the specific interferon, the default settings of $1.00 \mathrm{~g} / \mathrm{mL}$, $1.002 \mathrm{cP}$, and $0.73 \mathrm{ml} / \mathrm{g}$, respectively were utilized. Global fitting of the sedimentation velocity data for IFN- $\alpha 2 \mathrm{c}$ at all three concentrations was performed using the global analysis software SEDPHAT (31). The raw data were modeled with Lamm equation solutions that described sedimentation of a monomer-dimer-tetramer interaction scheme with rapid disassociation kinetics (31). The molecular weight of the monomer was fixed at $18.4 \mathrm{kDa}$ (the value obtained for a CM3 monomer), while the sedimentation coefficients and binding constants of the IFN$\alpha 2 \mathrm{c}$ species were allowed to float during the optimization process. The quality of the fit was judged by the magnitude of the root-mean-square deviations of the fit to the raw data (rmsd $\leq$ 0.0054), and by the randomness of the residuals.

\section{Native electrophoresis and immunoblot}

IFNAR2-EC (0.04 nmol), IFN (0.05 nmol) or IFN receptor complex were loaded onto 10\% tris-glycine gel without SDS (Invitrogen) and run under native electrophoresis conditions (125V, approximate current 6-12 mA/gel for 2 hours). Novex Tris-Glycine Native Running Buffer (Invitrogen) and Novex Native Tris-Glycine Sample buffer (Invitrogen) with complete absence of denaturants were used. For preparation of IFN receptor complex either $0.05 \mathrm{nmol}$ of IFN was incubated with $0.04 \mathrm{nmol}$ IFNAR2-EC at $37^{\circ} \mathrm{C}$ for 1 hour or $0.05 \mathrm{nmol}$ of the first IFN was incubated with $0.04 \mathrm{nmol}$ of IFNAR2-EC and then $0.05 \mathrm{nmol}$ of second IFN was added for an additional hour at $37^{\circ} \mathrm{C}$. For the different sample mixtures, final concentrations in the reaction volume were between 6.5-9.5 $\mu \mathrm{M}$ for IFNAR2-EC and 8.1-13.5 $\mu \mathrm{M}$ for each IFN. In experiments with IFNAR2-EC mutants, final concentrations in the reaction volume were between 7.3-10.0 $\mu \mathrm{M}$ for IFNAR2-EC mutants and 9.1-12.5 $\mu \mathrm{M}$ for each IFN. After native gel electrophoresis, gels were either stained using Sypro Ruby (Molecular Probes, Invitrogen Corp., Eugene, OR) and destained (10\% methanol / $7 \%$ acetic acid for 30 minutes), or processed for immunoblotting. Polyvinyldifluoride (PVDF) membranes (Bio-Rad Laboratories, Hercules, CA), Novex Tris Glycine Transfer Buffer (Invitrogen) supplemented with $20 \%$ methanol were used for immunoblot. Proteins were blotted with a constant voltage of $25 \mathrm{~V}$ for 2 hours. After blocking with non-fat dry milk (Bio-Rad), the membranes were incubated for 1 hour with supernatants containing different $\mathrm{N}$-terminal anti-IFN mAbs, at concentrations of 5-10 $\mu \mathrm{g} / \mathrm{ml}$. Peroxidase-labeled goat anti-mouse $\operatorname{IgG}(\mathrm{H}+\mathrm{L})$ (Southern Biotech, Birmingham, AL) diluted 1:4000 was used as secondary antibody. Signal was detected with SuperSignal West Pico kit (Pierce). For detection of histidine-tagged recombinant IFNs, nickel-activated horseradish peroxidase and SuperSignal West His probe TM Kit (Pierce) were used.

Stained membranes were visualized with a LAS-3000 CCD camera system (FUJIFILM Medical Systems, Stamford, CT) and gels were visualized on a UV lamp at 260-290 nm and digitized using a Kodak EDAS 290 (Eastman Kodak, Rochester, NY). After detection of signal, PVDF membranes were restored in western blot stripping buffer (Pierce) and reprobed. 


\section{Electroelution}

IFN-receptor complexes $(0.5 \mathrm{nmol}$ of each IFN $+0.4 \mathrm{nmol}$ of IFNAR2-EC) were run in a native gel (10\% Tris-Glycine, 5-well gels) under conditions described above. Gels were stained with Sypro Ruby (Invitrogen) and gel slices containing the protein complexes were excised and transfer into GeBAflex- midi tubes with 3500 Da cut-off (Gene Bio-Application Ltd., KfarHanagid, Israel). Electroelution was done in Novex Tris-Glycine SDS Running Buffer (Invitrogen) in horizontal electrophoretic apparatus 2 hours $/ 100 \mathrm{~V}$ and reverse polarity for 120 sec, using Gel extraction kit (Gene Bio-Application Ltd.). After electroelution, protein solution was transferred into a fresh tube for trichloroacetic acid (TCA) precipitation to prepare samples for mass spectrometry (MS) as described in Gel extraction handbook (Gene Bio-Application Ltd.). To increase protein precipitation yield, samples were incubated overnight at $-20^{\circ} \mathrm{C}$ with $98 \%$ acetone. After air-drying, the pellet was resuspended using $20 \mu \mathrm{l}$ of $0.1 \mathrm{M} \mathrm{NaOH}$. Samples were analyzed by reducing SDS PAGE using 10-20\% Tris-glycine gels (Invitrogen), as described earlier, followed by Sypro Ruby staining (Invitrogen), or mass spectrometry.

\section{Protein identification by mass spectrometry}

Protein identification of 1D gel separated proteins was performed on reduced and alkylated, trypsin digested samples prepared by standard MS protocols. Tryptic digests were analyzed by coupling the Nanomate (Advion BioSciences, Ithaca, NY), an automated chip-based nanoelectrospray unit to a quadrupole-time of flight mass spectrometer- QStarXL MS/MS System (Applied Biosystems/Sciex, Framingham, MA). Computer-controlled data-dependent automated switching to MS/MS provided peptide sequence information. AnalystQS software (Applied Biosystems/Sciex) was used for data acquisition. Data processing and databank searching were performed with Mascot software (Matrix Science, Beachwood, OH). The NCBInr protein database from the National Center for Biotechnology Information, NLM/NIH was used for the search analysis.

\section{Antiviral and antiproliferative assays, and neutralization of antiproliferative activities of IFNs with solubile IFNAR2-EC}

Antiviral and antiproliferative assays were performed as previously described $(9,12,32)$. MDBK cells were used for antiviral assays. All IFN units are expressed with reference to the NIH human recombinant IFN- $\alpha 2$ a standard Gxa01-901-535. For the antiproliferative assay, Daudi cells were treated with a single IFN at the initial concentration $360 \mathrm{ng} / \mathrm{ml}$. For neutralization of antiproliferative activity, Daudi cells were mock treated or treated with IFN$\alpha 2 \mathrm{c}, \mathrm{CM} 3$, or their mixture (tenfold dilutions from an initial concentration of $360 \mathrm{ng} / \mathrm{ml}$ for single IFN, or $360 \mathrm{ng} / \mathrm{ml}+360 \mathrm{ng} / \mathrm{ml}$ from equimolar IFNs mixture) with or without IFNAR2EC (at a constant concentration of $5 \mu \mathrm{g} / \mathrm{ml}$ ). Concentrations of IFNs that inhibit cell growth by $50 \%$ were calculated at 48 hour time point.

\section{Results}

\section{Examination of the interaction between two IFN-as and IFNAR2-EC by ELISA}

To test whether two IFN- $\alpha$ s could differentially interact with IFNAR2-EC, a competitive sandwich IFNAR2-EC ELISA was developed. The following criteria needed to be fulfilled: (1) Each of the IFNs should be specifically recognized by a specific anti-IFN monoclonal antibody after interaction with IFNAR2-EC. (2) An antibody selected for one IFN- $\alpha$ subtype should not exhibit any significant cross-reactivity with the other subtype. Based on these criteria and results from sandwich IFNAR2-EC ELISA I (supplementary material 1) the following IFN pair was selected: IFN- $\alpha 2 c-6$-histidine-tag, specifically recognized by mAb N27 (epitope 43-53) and hybrid CM3-6-histidine-tag, specifically recognized by mAb 1-36 (epitope 63-85). Neither mAb N27 nor mAb 1-36 cross-reacted with the other IFN. This IFN pair was 
used to address the question whether there is a kinetic influence between IFN- $\alpha$ s during interaction on IFNAR2-EC.

Conditions for saturation of immobilized IFNAR2-EC with the IFN pair (IFN- $\alpha 2 c-6$-histdinetag, CM3-6-histidine-tag) as well as monoclonal antibodies (N27, 1-36) were determined using a sandwich IFNAR2-EC ELISA II. Incubation of $15 \mu \mathrm{g} / \mathrm{ml}$ of IFN- $\alpha 2 \mathrm{c}-6$-histidine-tag or 150 $\mathrm{ug} / \mathrm{ml} \mathrm{CM} 3-6$-histidine-tag for 3 hours completely saturated $3 \mu \mathrm{g} / \mathrm{ml}$ of coated IFNAR2-EC (supplementary material 2). The 3-hour incubation required to saturate IFNAR2-EC is in agreement with recently published data (33). Based on these findings we developed a competitive sandwich IFNAR2-EC ELISA to examine the binding of two IFN species (CM3-6histidine-tag and IFN- $\alpha 2 \mathrm{c}-6$-histidine-tag) to the receptor subunit IFNAR2-EC.

In those experiments, the receptor subunit was immobilized on the ELISA plate. The results from the competitive sandwich IFNAR2-EC ELISA were compared with those from the sandwich IFNAR2-EC ELISA (where IFN- $\alpha 2 c-6$-histidine-tag or CM3-6-histidine-tag had been added to IFNAR2-EC at different concentrations). We found that after saturation of IFNAR2-EC with CM3-6-histidine-tag, the receptor subunit was still able to bind IFN- $\alpha 2 c-6$ histidine-tag with low displacement of CM3-6-histidine-tag (Figure 1A, curve: CM3-his + IFN- $\alpha 2 c-h i s+1-36$ ). However, after IFNAR2-EC was saturated with IFN- $\alpha 2 c-6$-histidine-tag, the binding of CM3-6-histidine tag was less effective (Figure 1B, curve: CM3-his + IFN- $\alpha 2 c-$ his $+1-36)$. The data appear to show that two IFN- $\alpha$ subtypes could bind simultaneously to IFNAR2-EC without significantly affecting each other's binding to IFNAR2-EC. Since ELISA is a semi-quantitative method, a more precise method (SPR) was employed to clarify this observation.

\section{Analysis of IFN- $\alpha 2 c$ and CM3 interaction with IFNAR2-EC by SPR}

To study the interaction of IFN- $\alpha 2 \mathrm{c}$ and CM3 with IFNAR2-EC in real-time and with direct detection of surface-bound protein, we used a surface plasmon resonance biosensor. First, we immobilized IFN- $\alpha 2 \mathrm{c}$ or CM3, respectively, on the sensor chip surfaces and then examined their interaction with IFNAR2-EC, which was in solution. Traces \#1 and \#2 in Figure 2 show the binding of IFNAR2-EC at a concentration of $700 \mathrm{nM}$, which was found to be virtually saturating receptor binding in the above ELISA assay. The binding of IFNAR2-EC to each of the immobilized interferons was significantly inhibited by the addition of soluble IFN- $\alpha 2 \mathrm{c}$ $(1600 \mathrm{nM})$ or CM3 $(900 \mathrm{nM})$ to the receptor in solution (Figure 2, traces \#1A and \#2A). The dissociation of IFNAR2-EC from the complex with each interferon was relatively fast and complete, so that no chip surface regeneration was necessary. When injecting IFN- $\alpha 2 \mathrm{c}$ or CM3 during the dissociation phase as soluble competitor to the surface immobilized sites, neither competitor accelerated the dissociation rate of the pre-formed complex of IFNAR2-EC, indicating the absence of rebinding (data not shown). Thus we can conclude that, in the configuration when IFN- $\alpha 2 \mathrm{c}$ or CM3 is immobilized on the chip surface, they interact with IFNAR2-EC similarly and competitively, with association rate constants well below the transport limited regime.

To probe the interaction in more detail, our next step was to change the configuration of the experiments and covalently immobilize IFNAR2-EC on the chip surfaces (to the level of 1200 - surface 1,1345 - surface 2, 1230 - surface 3 , and 1300 - surface 4 RUs), producing active surface site densities similar to those used above. We then examined the receptor interaction with IFN- $\alpha 2 \mathrm{c}, \mathrm{CM} 3$, and their equimolar mixture (Figure 2, trace \#3, 4, 5, respectively). Again, both interferons were in solution at concentrations sufficient to attain virtual saturation $(800 \mathrm{nM})$. The maximum level of binding $\left(R_{\max }\right)$ was $690 \mathrm{RU}$ for IFN- $\alpha 2 \mathrm{c}$ (surface 1), $560 \mathrm{RU}$ for CM3 (surface 2), and $530 \mathrm{RU}$ (surface 3) for their equimolar mixture. The value of $R_{\max }$ for the mixture did not exceed the $R_{\max }$ for any of the interferons alone. These results indicated that interferons did not appear to have independent binding sites on the 
immobilized IFNAR2-EC, consistent with the solution competition experiment above (Figure 3 , traces \#1 and \#2).

As can be easily discerned from comparing traces \#1 with \#3, and \#2 with \#4 (Figure 2), respectively, the measured binding kinetics changed significantly dependent on whether the IFNAR2-EC was immobilized or chosen as the soluble binding partner. Since a simple bimolecular reaction is invariant when the interacting molecules change place of which is kept in the surface and bulk phase, this indicates that a different, more complicated binding mechanism is present. This is supported by the attempt to quantify this result and fit $a d$ hoc the simple pseudo-first order rate equations to the binding traces: "The best-fit apparent rate constants for IFN- $\alpha 2$ c/IFNAR2-EC were $\mathrm{K}_{\mathrm{D}}{ }^{(\mathrm{app})}=6.6 \times 10^{-7} \mathrm{M}$ and $\mathrm{k}_{\text {on }}{ }^{(\mathrm{app})}=4.5 \times 10^{4}$

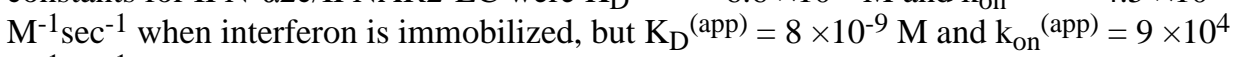
$\mathrm{M}^{-1} \mathrm{sec}^{-1}$ when the receptor is immobilized (fitting several traces at concentrations between 0.8 and $800 \mathrm{nM}$, data not shown)". Similarly, the best-fit off-rate rate constants for CM3/ IFNAR2-EC are $\mathrm{k}_{\mathrm{off}}{ }^{(\mathrm{app})}=3.0 \times 10^{-2} \mathrm{sec}^{-1}$ when interferon is immobilized, but $\mathrm{k}_{\mathrm{off}}{ }^{(\mathrm{app})}=7.0$ $\times 10^{-4} \mathrm{sec}^{-1}$ when the receptor is immobilized (in the presence of soluble competitor, see below). Further, in each case, there are large residuals of the fit indicating that this model must be rejected. One can conclude that the apparent binding constants from the ad hoc fit with the simple bimolecular reaction model do not reflect the true molecular properties, in neither case. It is therefore also not surprising that the parameter estimates from the wrong model differ by two orders of magnitude from the different experimental designs.

A further observation from the second experiment is that the two interferons interacted with the immobilized receptor differently because the dissociation of IFN- $\alpha 2 \mathrm{c}$ from IFNAR2-EC was significantly faster than that of CM3 and the dissociation of their mixture proceeded at an intermediate rate (data not shown). Interestingly, in this configuration we found a strong rebinding effect in the case of $\mathrm{CM} 3$, but only a very weak one in the case of IFN- $\alpha 2 \mathrm{c}$ dissociation from immobilized IFNAR2-EC. The evidence of rebinding was an increase in the rate of interferon dissociation in the presence of the soluble receptor $(\sim 30$ and $\sim 1.2$ times for CM3 and IFN- $\alpha 2 c$, respectively, data not shown). Since we have shown the absence of mass transport limitation in the first experiment, again, the appearance of a strong rebinding effect for CM3 in the configuration of the second experiment, again, cannot be explained on the basis of a simple bimolecular reaction (even allowing for some degree of size- and chargedependence of the diffusional permeability of the immobilization matrix (34). One hypothetical effect that may cause such a behavior could be preferential immobilization of IFNAR2-EC in a conformational state (due to secondary or tertiary structural changes) that exhibits a higher on-rate constant for CM3, as compared to the conformational state when the receptor is in free solution.) In addition, as will be described below, there is oligomerization of IFN- $\alpha 2 \mathrm{c}$ in solution, which will be dominant for the surface dissociation behavior due to the high local concentrations in the immobilization matrix of the SPR sensor. Unfortunately, these factors make it impossible to arrive at a reliable and unambiguous quantitative interpretation of the binding kinetics (35).

It should be noted that the application of a mixture of the two interferon molecules produced virtually no additional binding to the immobilized IFNAR2-EC that exceeded the binding of one of the interferon molecule alone, indicating competition for sites on the immobilized receptor (Figure 2 trace \#5, and Figure 3 trace \#2 below). While unexpected on the basis of the ELISA experiments showing only moderate competition, together with the observation that receptor immobilization substantially changed the binding properties in SPR, this result may indicate that differences in the immobilization and/or surface properties may have significant impact on the receptor conformation and consequently binding of soluble IFN. In fact, interpreting the $50 \%$ binding level as a gross estimate of an empirical $\mathrm{K}_{\mathrm{D}}$ of the ELISA titrations with each individual IFN, the affinity of the receptor in the ELISA experiments is in the high 
nanomolar and low micromolar range, respectively, which is substantially higher than the SPR results indicate (and as compared estimates of affinity in the literature [14]). Therefore, we interpret the receptor state immobilized on the SPR surface more representative of the native state.

In our next experiment, when CM3 was injected over surface 4 that had been saturated with the pre-formed IFNAR2-EC-IFN- $\alpha 2 \mathrm{c}$ complex (similar to surface 1, $1250+/-100 \mathrm{RU}$ ), the surface-bound complex became significantly stabilized, thus making the binding practically irreversible (Figure 3, trace \#2). Some of the dissociation signal can be attributed to the CM3 having formed complexes with empty receptor sites that arose both from incomplete initial saturation and from sites vacated during the initial dissociation of IFN- $\alpha 2$ c/receptor complexes. However, if CM3 did not influence the pre-bound IFN- $\alpha 2$ c/receptor complexes as well, then the signals from dissociating $\mathrm{CM} 3 /$ receptor and IFN- $\alpha 2$ c/receptor complexes should be strictly additive, and after CM3 application, the kinetic curve of dissociation would be expected to have a slope at least as steep or steeper than that of trace \#1 in Figure 3. The data also cannot be explained by a rebinding-related kinetic exchange mechanism due to the virtual absence of rebinding for IFN- $\alpha 2 \mathrm{c}$ from the immobilized receptor. Therefore, the decrease of the dissociation rate (trace \#2) indicated the interaction of CM3 with the pre-formed IFN- $\alpha 2 \mathrm{c}$ IFNAR2-EC complex. In order to establish whether this interaction resulted in an exchange of CM3 for IFN- $\alpha 2 \mathrm{c}$ in the IFN/receptor complex, we probed the sensor surface during the slow dissociation by application of the N27 antibody (which also in the SPR experiment binds specifically to IFN- $\alpha 2 \mathrm{c}$ but not to CM3). Under conditions of trace \#2 at $\sim 1000 \mathrm{sec}, \mathrm{N} 27$ gave a large surface binding signal (data not shown), demonstrating that IFN- $\alpha 2 \mathrm{c}$ was still present at the surface after interaction of CM3 with preformed IFN- $\alpha 2$ c/IFNAR2-EC. Thus, CM3 does not appear to have completely replaced IFN- $\alpha 2 \mathrm{c}$ on the pre-formed IFN- $\alpha 2 \mathrm{c} /$ receptor complexes, although contributions via this mechanism cannot be excluded. Possible other mechanisms include induced conformational changes in the IFN- $\alpha 2$ c/IFNAR2-EC complex by transient formation of triple complexes in the presence of excess CM3, or, alternatively, a hetero-oligomerization of the IFN/receptor complexes, or more complex schemes involving effects on the self-association of IFN- $\alpha 2 \mathrm{c}$ modulating its binding avidity to the receptorfunctionalized SPR surface (see below).

\section{Analysis of IFN- $\alpha 2 c$ and $\mathrm{CM} 3$ oligomeric state in solution}

In order to gain more insight in to the possible binding mechanisms, and the differences in receptor binding observed in SPR, the oligomeric state of both IFN molecules were studied by sedimentation velocity analytical ultracentrifugation.

The rate of migration of the interferons through a centrifugal field was monitored using analytical ultracentrifugation sedimentation velocity (AUC/SV). It is well-established that the rate at which a protein migrates through a centrifugal field is proportional to its mass and shape (36). A concentration dependent increase in the sedimentation coefficient would indicate an increase in the protein mass and therefore diagnostic of self-association. The sedimentation coefficient distribution resulting from the analysis of the CM3 solutions is shown in Figure 4. The major peak had a weight-average sedimentation coefficient $\left(\mathrm{s}_{\mathrm{w}}\right)$ of $1.9 \mathrm{~S}$ and was independent of loading concentration (Figure 4, trace \# 1,2), indicating the absence of CM3 self-association.

The sedimentation profile of IFN- $\alpha 2 \mathrm{c}$ was in sharp contrast to CM3. At the lowest IFN- $\alpha 2 \mathrm{c}$ concentration, the $\mathrm{c}(\mathrm{s})$ distribution consisted of a single broad peak with a weight-average sedimentation coefficient $\left(s_{\mathrm{w}}\right)$ of $2.6 \mathrm{~S}$ (Figure 4 , trace \# 3 ). This value is approximately $35 \%$ larger than what was obtained for CM3 monomer. Furthermore, as the loading concentration of IFN- $\alpha 2 \mathrm{c}$ increased, the $\mathrm{c}(\mathrm{s})$ distribution became bimodal and the weight average sedimentation coefficient of the entire distribution shifted toward a larger $s_{\mathrm{w}}$ value (3.4S) 
indicating an increase of the average molecular weight (Figure 4, trace \# 4). At the highest concentration, the $\mathrm{s}_{\mathrm{w}}$ increased further to $3.9 \mathrm{~S}$, with the fastest moving boundary fraction sedimenting with $4.4 \mathrm{~S}$ (Figure 4, trace \# 5), corresponding to an estimated molar mass $\sim 3.5$ fold the monomer mass. The sedimentation velocity data can be described well $(\mathrm{rmsd}=0.005)$ with a global model of Lamm equation solutions (31) for rapid monomer-dimer-tetramer selfassociation with $\Delta \mathrm{G}_{12}=-6.6 \mathrm{kCal} / \mathrm{mol}$ corresponding to a $\mathrm{K}_{\mathrm{d}}$ value, in three dimensions, of 10 micromolar and $\Delta \mathrm{G}_{24}$ of $=-6.4 \mathrm{kCal} / \mathrm{mol}$ ( $\mathrm{K}_{\mathrm{d}}$ of 15 micromolar in three dimensions).

We studied the presence of hetero-association of IFN- $\alpha 2 \mathrm{c}$ and CM3 in solution in a simplified assay, by comparing the weight-average s-values of IFN- $\alpha 2 \mathrm{c}$ measured at $0.4 \mathrm{mg} / \mathrm{ml}$ with that measured in the presence of additional $0.5 \mathrm{mg} / \mathrm{ml} \mathrm{CM} 3$. The measured signal-average value of the mixture of $2.86 \mathrm{~S}$ is $\sim 5.5 \%$ larger than the theoretically expected $\mathrm{s}_{\mathrm{w}}$-value for a noninteracting mixture. This shows that CM3 does not or only very weakly interact with IFN- $\alpha 2 \mathrm{c}$ in solution.

While the free energies of self-association of IFN- $\alpha 2 \mathrm{c}$ are likely too low to influence the initial binding step to the receptor, they support the presence of a more complex binding scheme where self-association of IFN- $\alpha 2 \mathrm{c}$ could contribute to receptor oligomerization processes in the cell membrane. In the present context, the self-association is highly relevant under the conditions of the SPR experiment, for which average concentrations in the high $\mu \mathrm{M}$ range exist in the immobilization matrix on the biosensor surface. This leads to an avidity effect causing the dissociation to proceed at a significantly slower rate constant than the intrinsic chemical dissociation rate constant. As a consequence, an alternative explanation of the effect seen in Figure 3 might be a possible influence of CM3 on the self-association of $\alpha 2 \mathrm{c}$. Due to the absence of solution interaction between the two IFNs, such an effect either would have to be mediated by the receptor, or involve different conformations of IFN- $\alpha 2 \mathrm{c}$ in complex with the receptor that can interact with CM3.

\section{IFN receptor complex in solution}

During ELISA experiments and SPR analysis, proteins were immobilized on the surface. Subsequently, we examined the competition between IFNs for IFNAR2-EC binding in solution. Reaction mixtures, containing different IFN subvariants (Figure 5) after incubation with IFNAR2-EC, were run under native electrophoretic conditions followed by Western blot. If both IFNs (IFN- $\alpha 2 c$ and CM3) are present at the same time on an IFNAR2-EC complex, it was hypothesized, that they would be recognized by both IFN-specific mAbs (1-36: CM3 and N27: IFN- $\alpha 2 c$ ), and that would confirm presence of two different IFNs (IFN- $\alpha 2 \mathrm{c}$ and CM3) on one IFNAR2-EC. Unfortunately, mAb 1/36 showed a diminished activity with CM3 in immunoblot after native electrophoresis (data not shown). Moreover, in electrophoresis under native conditions IFNAR2-EC-CM3 and IFNAR2-EC-IFN- $\alpha 2 c$ complexes overlapped in the same position of the gel. Thus, it was not possible to distinguish between heterodimeric IFN/ receptor complexes comprised of IFNAR2-EC and either IFN- $\alpha 2 \mathrm{c}$ or CM3, and trimeric complexes containing the receptor and both interferons using this technique. However as was previously observed (24), IFNAR2-EC-IFN- $\alpha 2 c-6$-histidine-tag migrates in native electrophoresis at a higher position than IFNAR2-EC-IFN- $\alpha 2 \mathrm{c}$ complex. Therefore, a combination of the above mentioned IFNs with and without N-terminal 6-histidine tag was used to assess the presence of two different IFNs (IFN- $\alpha 2 \mathrm{c}$ and CM3-6-histidine-tag or IFN$\alpha 2 c-6$-histidine-tag and CM3) on one IFNAR2-EC. As a control, each IFN was subjected to electrophoresis separately. In order to examine if there was a nonspecific interaction between the two IFNs, a mixture of both IFNs were electrophoresed. No interaction was observed under these conditions. Subsequently the IFN/receptor mixture was prepared by incubating each IFN with IFNAR2-EC separately, or by incubating the one IFN with IFNAR2-EC and than adding the second one (preparation described in materials and methods section). Two identical sets of 
samples were examined by electrophoresis. One gel was stained with Sypro Ruby (Figure 5A), and the second one was used for immunoblot (Figures 5B-D). The presence of IFNAR2-EC in IFNs receptor complexes was confirmed by anti- IFNAR2-EC mAb 46.10 (Figure 5B); IFN$\alpha 2 \mathrm{c}$ was detected with mAb N27 (Figure 5C), and the presence of IFNs with 6-histidine-tag was confirmed with mAbs recognizing the tag (Figure 5D). The same membrane after stripping was used for all three immunoblots to minimize differences between experiments. After individual incubation of each IFN with IFNAR2-EC the presence of two types of IFN-IFNAR2EC bands were observed (the first type contained hybrid CM3-6-histidine-tag or IFN- $\alpha 2 c-6$ histidine-tag and moves in the gel at a higher position, and the second type contained hybrid $\mathrm{CM} 3$ or IFN- $\alpha 2 \mathrm{c}$ and moves in a lower position, Figure $5 \mathrm{~A}, \mathrm{~B}, \mathrm{C}$ and $\mathrm{D})$. The incubation of two IFNs (with and one without N-terminal 6-histidine-tag) with IFNAR2-EC resulted in formation of two types of IFN-receptor bands \{IFNAR2-EC-IFN-( $\alpha 2 \mathrm{c}$ or CM3)-6-histidinetag complex and IFNAR2-EC-IFN-( $\alpha 2 \mathrm{c}$ or CM3) $\}$ complex, Figure 5A, lanes 7, 8, 9, 10). Thus, IFN- $\alpha$ species appear to compete for the receptor binding site. Moreover, IFN- $\alpha 2 \mathrm{c}$ is a better competitor than CM3, and the N-terminal 6-histidine tag seems not to affect the ability of IFN$\alpha 2 \mathrm{c}$ to compete for IFNAR2-EC. The results from native electrophoresis showed quantitatively lower amounts of CM3-receptor complex than IFN- $\alpha 2 c$-receptor complex (Figure 5A, B), and not even an increase in incubation time or the amount of CM3 would lead to an increase in the quantity of CM3-receptor complexes (supplementary material 3). The presence of a N-terminal 6-histidine tag decreased the competitive ability of CM3 (Figure 5A, lane 11). The most interesting result was observed in immunoblot (Figure 5D, lane 10). Lane 10 should contain IFN-receptor complex formed mostly by IFN- $\alpha 2 c-6$-histidine-tag and IFNAR2-EC. However, the anti-6-histidine-tag $\mathrm{mAb}$ had difficulties recognizing this IFN. This band should have been as intense as the band in lane 8 (Figure 5D) (just as the corresponding signals from the N27 antibody recognizing $\alpha 2 \mathrm{c}$ directly are equally intense). This observation raised the possibility that the lesser intensity of band could be due to the presence of the second IFN (CM3). Since we were not able to detect $\mathrm{CM} 3$ with specific mAbs in Western blot, we repeated the native electrophoresis described above, cut bands A,B,C from the gel (Figure 6A), performed electroelution, and analyzed the samples by both electrospray ionization mass spectrometry (ESI-MS, supplementary material 4), and separation of proteins using SDS PAGE under reducing conditions in 10-20\% Tris-glycine gels (Figure 6B). Both analyses confirmed presence of two IFNs (IFN- $\alpha 2 \mathrm{c}-6$-histidine-tag, CM3) and IFNAR2-EC in the band A (Figures $6 \mathrm{~A}, \mathrm{~B}$, and supplementary material 4$)$.

In summary, the native electrophoresis experiments show the IFNs to be largely competitive, but also allowed to detect a population of triple complexes with both IFNs. Considering the much higher protein concentrations used in the electrophoresis assay as compared to the SPR experiments (where CM3 did not lead to additional signal over preformed IFN- $\alpha 2$ c/receptor complexes at $800 \mathrm{nM} \mathrm{CM} 3$ ) this would be consistent with a $\mathrm{K}_{\mathrm{D}}$ of CM3 for pre-formed IFN$\alpha 2 \mathrm{c} /$ receptor complexes in the $10 \mu \mathrm{M}$ range or higher.

\section{IFNAR2-EC mutants}

IFNAR2-EC mutants used in this part of the study were selected based on sandwich IFN ELISA assays (Drs. G. Schreiber and T. Peleg-Schulman, personal communication). Differences in $\mathrm{K}_{\mathrm{D}}$ values between IFN- $\alpha 2 \mathrm{c}$ and CM3 were observed for IFNAR2-EC mutants I105A and M48V (data not shown). The importance of those amino acids for interaction with helices A (45-50) and $\mathrm{E}$ (102-106), as well as loop $\mathrm{AB}(78-82)$ of IFN- $\alpha 2$ has also previously been shown by Piehler et al. $(1999,2000)$. We used native electrophoresis to study differences in binding between CM3 with and without 6-histidine-tag and IFN- $\alpha 2 \mathrm{c}$ with or without 6-histidine-tag and the IFNAR2-EC mutants I47A, I105A and M48V. We observed differences in binding between the aforementioned IFN species for IFNAR2-EC mutants I105A and I47A. IFN- $\alpha 2 \mathrm{c}$ was able to bind to mutants I105A and I47A but CM3 did not form a complex with these 
receptor mutants (Figure 7A, B). Interestingly enough, these differences had not been observed in the same experiments with IFN- $\alpha 21 b$ (data not show). Since it was confirmed that helix C is not involved in interaction with IFNAR2-EC $(19,23)$, these results suggested that mutation in helix C (CM3) could affect IFN-IFNAR2-EC indirectly. The presence or absence of Nterminal 6-histidine tag had no effect on behavior of CM3. The above described results show that different IFNs could utilize different amino acids on IFNAR2-EC for binding.

\section{Neutralization of antiproliferative activities of interferons on Daudi cells with solubile IFNAR2-EC}

Results of the neutralization assay show that IFNAR2-EC neutralized both IFNs to the same degree, suggesting that IFN- $\alpha 2 \mathrm{c}$ and $\mathrm{CM} 3$ are binding to IFNAR2-EC with similar affinity. This observation lead to the conclusion that differences between IFN- $\alpha 2 \mathrm{c}$ and $\mathrm{CM} 3$ in antiproliferative assay are not due to problems in interaction with IFNAR2. Moreover, incubation of a mixture of IFNs with IFNAR2-EC in cell-based experiments support evidence that CM3 competes less effectively for IFNAR2-EC than IFN- $\alpha 2 c$, by virtue of the fact that neutralizing effect of IFNAR2-EC on IFN- $\alpha 2 \mathrm{c}$ was not decreased by the presence of CM3 (Table 1). Thus, lower competition of CM3 could be explained by utilization of different amino acids in the binding region of IFNAR2-EC rather than differences in affinity.

\section{Discussion}

The IFN/receptor interaction is critical in determining the extent of the subsequent biological response $(5,37,38)$. Differences in spectra of biological activities among members of the IFN$\alpha$ family indicate that each subtype could exhibit differences in receptor binding and/or intracellular signaling.

Our previous results showed that hybrid IFNs with N-terminal portion derived from IFN- $\alpha 21 \mathrm{~b}$ competed poorly with IFN- $\alpha 2 b$ for cellular binding $(12,17)$. CM3 is one of these hybrids, and also has a mutation in helix C (Y86K). Structural changes in helix C may influence interaction with IFNAR1, a component of the type I interferon receptor which is considered important for IFN antiproliferative activity (19). This could explain the tenfold lower antiproliferative activity of CM3 than that of IFN- $\alpha 2 \mathrm{c}$ in 48 hours antiproliferative assay. It did however not explain the 800-fold lower ability of CM3 (with 6-histidine tag) to compete with IFN- $\alpha 2 \mathrm{c}$ (with 6-histidine tag) for receptor binding site (17).

This observation raised the question, whether interaction among two individual IFN- $\alpha$ s and IFNAR2-EC contribute to the observed poor competition. To explore this question, we analyzed the binding of IFN- $\alpha 2 \mathrm{c}$ and hybrid CM3 with IFNAR2-EC using defined anti-IFN mAbs in competitive binding ELISA, native electrophoresis followed by Western blot, ESIMS, SPR analysis and neutralization assay.

The data from competitive binding ELISA appear to show that two IFN- $\alpha$ subtypes could bind simultaneously to IFNAR2-EC without significantly affecting each other's binding to IFNAR2EC. Only IFNs with N-terminal 6-histidine-tag were used in all ELISA experiment, due to the fact that mAbs only recognized IFNs with 6-histidine-tag after binding to IFNAR2-EC. This could be explained by influence of the 6-histidine-tag on IFN structure (24).

In order to approach the surface binding observed by ELISA in a more quantitative way, further analysis of the interaction of IFN- $\alpha 2 \mathrm{c}$ and CM3 with IFNAR2-EC was done using SPR optical biosensing. To exclude any negative effect a tag might have on interaction, we used IFNs without N-terminal 6-histidine-tag in these experiments. SPR optical biosensing is a technology that provides real time information on the course of the interaction, and is similar to ELISA in that it requires the immobilization of one of the interacting compounds. It does 
not, however, require the use of antibodies. Because of the surface, two experimental designs were possible: one, where the interferons were covalently attached to the chip surface, while the receptor was in solution, and the other, with the reverse configuration. Strikingly different binding curves were detected in the different configurations, pointing to a more complex interaction mechanism.

In the configurations where IFN- $\alpha 2 \mathrm{c}$ or CM3 were immobilized on the chip surface, their interaction with IFNAR2-EC that was in solution was similar. Neither of the soluble interferons had any influence on the kinetics of dissociation of the pre-bound receptor. In the configuration in which IFNAR2-EC was immobilized, IFN- $\alpha 2 \mathrm{c}$ and CM3 each interacted differently with the receptor and $\mathrm{CM} 3$ affected the kinetics of dissociation of the pre-formed IFN- $\alpha 2 \mathrm{c} /$ receptor complex. One could hypothesize that during the formation of the interferon-surface-bound receptor complexes, different interferons might undergo small conformational changes, which may be mutually influenced by a transient interaction. With immobilized interferons, the immobilization constraints might prohibit the necessary conformational flexibility. Alternatively, lateral association or oligomerization of the receptor-interferon complex produced by their close proximity on the sensor chip surface might also play a role. This is emphasized by our observation from sedimentation velocity of the self-association in solution of IFN- $\alpha 2 c$, but no detectable self-association of CM3. While the SPR data did not confirm the presence of two individual IFN- $\alpha$ s on IFNAR2-EC, they showed that both IFNs influence each other during this interaction. The differences in results between ELISA and SPR could be due to the fact that these methods use different surfaces for immobilization of proteins. This could potentially lead to different results regarding the conformation and aggregation state of the surface-bound molecules. Further, the molecules used were slightly different (his-tag in ELISA versus no his-tag in SPR).

ELISA experiments and SPR analysis required immobilizing the proteins onto a surface. Thus the surface could contribute to structural changes of the proteins. To eliminate that possibility, protein-protein interactions were studied in solution, and detected by native electrophoresis and immunoblot. These experiments showed competition between IFN- $\alpha 2 \mathrm{c}$ and CM3 (with or without 6-histidine tag) for IFNAR2-EC. Moreover, ESI-MS analysis of bands representing IFN-receptor complexes that were cut from native PAGE gels confirmed the presence of two IFNs with the IFNAR2-EC at the same time in the band A. These results suggested that two IFNs could bind directly to IFNAR2-EC. However, binding of CM3 to the IFNAR2-EC portion of the IFNAR2-EC-IFN- $\alpha 2 c$ complex is probably weak and transient, since it is not able to release IFN- $\alpha 2 c$ from IFNAR2-EC interaction effectively. The presence of CM3 could affect the conformation of IFN- $\alpha 2 \mathrm{c}$, which could be an additional explanation why monoclonal antibody (anti-6-histidine-tag) recognized IFN- $\alpha 2 \mathrm{c}$ in the complex less effectively. Further studies and the use of different experimental approaches will be necessary to gain a detailed understanding of these interactions.

The generally observed lower quantity of CM3 (with or without 6-histidine-tag) receptor complexes could be explained by conditions in native electrophoresis that may cause some structural changes on CM3 molecule, which then could reduce interaction with IFNAR2-EC.

Experiments using IFNAR2-EC mutants in native electrophoresis showed that IFNAR2-EC mutations in positions 105 (I105A) and 47 (I47A) completely prevented interaction between CM3 (with or without 6-histidine tag) and the receptor subunit. These results provide evidence that CM3 (with or without 6-histidine tag) and IFN- $\alpha 2 \mathrm{c}$ (with or without 6-histidine tag) could use different amino acids within the binding domain of IFNAR2-EC. Similar results had been observed for IFN- $\alpha 2 \mathrm{c}$ versus IFN- $\beta$, where mutating IFNAR2-EC (W102A) proved to be most destructive for IFN- $\beta$ binding $(22,39)$. Because IFNs mutually influence each other during competition, binding domains are probably in close proximity or overlapping (22). 
Cell-based neutralization assays with IFNAR2-EC show the same neutralization effect on CM3 and IFN- $\alpha 2 \mathrm{c}$. Thus the utilization of different amino acids in the binding region of IFNAR2 could help explain the better competitive ability of IFN- $\alpha 2 \mathrm{c}$ compared to that of CM3. Moreover, these results strengthen evidence that the mutation in helix $\mathrm{C}$ had no impact on interaction with IFNAR2. The difference between the two IFNs observed in antiproliferative assay could be a consequence of interaction with IFNAR1 (19).

In conclusion, the results of this study show the complexity of the interaction among different IFN- $\alpha$ subtypes during the process of binding to IFNAR2-EC. They underscore the importance of the differences in interaction on the amino acid level during this process, which could help understand the significance of the existence of the various IFN-as subtypes.

\section{Supplementary Material}

Refer to Web version on PubMed Central for supplementary material.

\section{Acknowledgements}

We thank H. Nie (National Institute of Allergy and Infectious Diseases, NIAID ) for performing antiviral assays, Drs. J. Hartley, D. Esposito and W. Gillette (Center for Cancer Research - Core Resource NCI/SAIC) for expression and purification of IFN $\alpha 2 \mathrm{c}$ and CM3, R. Martin and Drs. C.H. Hammer and M. A. Robinson, (Research technology Branch, NIAID) for ESI-MS analysis and valuable discussions, Dr. M. Garfield (Research Technology Branch, NIAID) for sequencing protein. We also thanks Drs. G. Schreiber (Department of Biological Chemistry, Weizmann Institute of Science), D. Novick (Department of Molecular Genetics, Weizmann Institute of Science), F. Schmeisser (Food and Drug Administration), P. McPhie (National Institute of Diabetes, Digestive and Kidney Diseases), A. Zhou (Department of Chemistry, Cleveland State University) and the NIH Fellows Editorial Board for reviewing the manuscript and valuable discussions.

$\dagger$ This research was supported in part by the Intramural Research Program of the NIH (NIAID) and by the Oak Ridge Institute for Science and Education's (ORISE) Research Associates program at NIH.

\section{References}

1. La Fleur DW, Nardelli B, Tsareva T, Mather D, Feng P, Semenuk M, Taylor K, Buergin M, Chinchilla D, Roshke V, Chen G, Ruben SM, Pita PM, Coleman TA, Moore PA. Interferon-kappa, a novel type I interferon expressed in human keratinocytes. J Biol Chem 2001;276:39765-39771. [PubMed: 11514542]

2. Conclin DC, Grant FJ, Rixon MW, Kindsvogel W. Interferon-e. U.S. Patent 6329175. 2002

3. Kontsek P, Karayianni-Vasconcelos G, Kontsekova E. The human interferon system: characterization and classification after discovery of novel members. Acta Virol 2003;47:201-215. [PubMed: 15068375]

4. Sen GC. Viruses and interferons. Annul Rev Microbiol 2001;55:255-281. [PubMed: 11544356]

5. Kontsek P. Human type I interferons: structure and function. Acta Virol 1994;38:345-360. [PubMed: 7793359]

6. Diaz MO, Bohlander S, Allen G. Nomenclature of the human interferon genes. J Interferon Cytokine Res 1996;16:179-180. [PubMed: 8742371]

7. Bekisz J, Schmeisser H, Hernandez J, Goldman ND, Zoon KC. Human IFNs $\alpha, \beta$, $\omega$. Review. Growth Factor 2004;4:243-251.

8. Pestka S. The human interferons from protein purification and sequence to cloning and expression: before, between and beyond. Arch Biochem Biophys 1983;221:585-589. [PubMed: 6340609]

9. Zoon KC, Miller D, Bekisz J, zur Nedden D, Enterline JC, Nguyen NY, Hu R. Purification and characterization of multiple components of human lymphoblastoid interferon- $\alpha$. J Biol Chem 1992;267:15210-15216. [PubMed: 1634550]

10. Takaoka A, Yanai H. Interferon signaling network in innate defence. Cell Microbiol 2006;8:907922. [PubMed: 16681834] 
11. Nyman TA, Tolo H, Parkkinen J, Kalkkinen N. Identification of nine interferon-alpha subtypes produced by Sendai virus - induced human peripheral blood leucocytes. Biochem J 1998;329:295302. [PubMed: 9425112]

12. Hu R, Gan Y, Liu J, Miller D, Zoon KC. Evidence for multiple binding sites for several components of human lymphoblastoid interferon- $\alpha$. J Biol Chem 1993;268:12591-12595. [PubMed: 8509399]

13. Novick D, Cohen B, Rubinstein $\mathrm{M}$. The human interferon $\alpha / \beta$ receptor: Characterization and molecular cloning. Cell 1994;77:391-400. [PubMed: 8181059]

14. Jaks E, Gavutis M, Uze G, Martal J, Piehler J. Differential receptor subunit affinities of type I interferons govern differential signal activation. J Mol Biol 2006;2:525-539. [PubMed: 17174979]

15. Mogensen KE, Lewerenz M, Reboul J, Lutfalla G, Uze G. The type I interferon receptor: Structure, function, and evolution of a family business. J Interferon Cytokine Res 1999;19:1069-1098. [PubMed: 10547147]

16. Uze G, Lutfalla G, Gresser I. Genetic transfer of a functional human interferon a receptor into mouse cells: Cloning and expression of its c DNA. Cell 1990;60:225-234. [PubMed: 2153461]

17. Hu R, Bekisz J, Schmeisser H, McPhie P, Zoon K. Human IFN- $\alpha$ protein engineering: The amino acid residues at positions 86 and 90 are important for antiproliferative activity. J Immunol 2001;167:1482-1489. [PubMed: 11466368]

18. Jaitin DA, Roisman LC, Jaks E, Gavutis M, Piehler J, Van der Heyden J, Uze G, Schreiber G. Inquiring into the differential action of interferons (IFNs): an IFN-alpha2 mutant with enhanced affinity to IFNAR1 is functionally similar to IFN-beta. Mol Cell Biol 2006;5:1888-1897. [PubMed: 16479007]

19. Roisman LC, Jaitin DA, Baker DP, Schreiber G. Mutational analysis of the IFNAR1 binding site on IFN $\alpha 2$ reveals the architecture of a weak ligand-receptor binding site. J Mol Biol 2005;353:271-281. [PubMed: 16171819]

20. Cajean-Feroldi C, Nosal F, Nardeus PC, Gallet X, Guymarho J, Baychelier F, Sempe P, Tovey MG, Escary JL, Eid P. Identification of residues of the IFNAR1 chain of the type I human interferon receptor critical for ligand binding and biological activity. Biochmemistry 2004;39:12498-12512.

21. Piehler J, Schreiber G. Biophysical analysis of the interaction of human Ifnar2 expressed in E. coli with IFN- $\alpha 2$. J Mol Biol 1999;289:57-67. [PubMed: 10339405]

22. Piehler J, Schreiber G. Mutational and structural analysis of the binding interface between type I IFNs and their receptor IFNAR2. J Mol Biol 1999;294:223-237. [PubMed: 10556041]

23. Piehler J, Roisman LC, Schreiber G. New structural and functional aspects of the type I interferonreceptor interaction revealed by comprehensive mutational analysis of the binding interface. J Biol Chem 2000;275:40425-40433. [PubMed: 10984492]

24. Schmeisser H, Kontsek P, Esposito D, Gillette W, Schreiber G, Zoon KC. Binding characteristids of interferon-a subvariants to IFNAR2-EC and influence of the 6-histidine tag. J Interferon Cytokine Res 2006;26:866-876. [PubMed: 17238829]

25. Ellman GL. Tissue sulfhydryl groups. Arch Biochem Biophys 1959;82:70-77. [PubMed: 13650640]

26. Kontsek P, Borecky L, Zav'yalov VP, Maiorov VA. Peptide-mapping of three neutralizing epitopes into predicted biologically active sites of human interferon- $\alpha 2$. Immunol Lett 1993;35:281-284. [PubMed: 7685736]

27. Alexenko AP, Izotova LS, Kostrov SV, Strongin AY. Mapping of an epitope of human leukocyte interferon A which is recognized by the murine monoclonal antibody NK2. Biomed Sci 1991;2:403409. [PubMed: 1724609]

28. Kontsek P, Borecky L, Kontsekova E, Kolcunova A, Novak M, Zav'yalov VP, Maiorov VA. Immunodominant structures in the aminoterminal portion of human interferon- $\alpha 1$. Molecular Immunology 1992;29:863-870. [PubMed: 1378930]

29. Arnheiter H, Thomas RM, Leist T, Fountoulakis M, Gutter B. Physiochemical and antigenic properties of synthetic fragments of human leukocyte interferon. Nature 1981;294:278-280. [PubMed: 6170893]

30. Svitel J, Balbo A, Mariuzza RA, Gonzales NR, Schuck P. Combined affinity and rate constant distributions of ligand populations from experimental surface binding kinetics and equilibria. Biophys J 2003;84:4062-4077. [PubMed: 12770910] 
31. Dam J, Velikovsky CA, Mariuzza RA, Urbanke C, Schuck P. Sedimentation velocity analysis of heterogeneous protein-protein interaction: Lamm equation modeling and sedimentation coefficient distributions c(s). Biophys J 2005;89:619-634. [PubMed: 15863475]

32. Yeh TJ, Mc Bridge PT, Overall JC Jr, Green JA. Automated, quantitative cytopathic effect reduction assay for interferon. J Clin Microbiol 1982;16:413-415. [PubMed: 6181091]

33. Schuck P. Kinetics of ligand binding to receptor immobilized in a polymer matrix, as detected with an evanescent wave biosensor. I. A computer simulation of the influence of mass transport. Biophys J 1996;70:1230-1249. [PubMed: 8785280]

34. McKenna SD, Vergilis K, Arulanandam ARN, Weiser WY, Nabioullin R, Tepper MA. Formation of human IFN- $\beta$ complex with the soluble type I interferon receptor IFNAR2 leads to enhanced IFN stability, pharmacokinetics, and antitumor activity in xenografted SCID mice. J Interferon Cytokine Res 2004;24:119-129. [PubMed: 14980076]

35. Schuck P. Use of surface plasmon resonance to probe the equilibrium and dynamic aspects of interactions between biological macromolecules. Annu Rev Biophys Biomol Struct 1997;26:541555. [PubMed: 9241429]

36. Lebowitz J, Lewis MS, Schuck P. Modern analytical ultracentrifugation in protein science: A tutorial review. Protein Sci 2002;11:2067-2079. [PubMed: 12192063]

37. Deonarain R, Chan DCM, Platanias LC, Fish EN. Interferon-alpha/beta receptor interactions: A complex story unfolding. Current Pharmaceutical Design 2002;8:2131-2137. [PubMed: 12369858]

38. Hu R, Bekisz J, Hayes M, Audet S, Beeler J, Petricoin E, Zoon KC. Divergence of binding, signaling, and biological responses to recombinant human hybrid IFN. J Immunol 1999;163:854-860. [PubMed: 10395679]

39. Peleg-Shulman T, Roisman LC, Zupkovitz G, Schreiber G. Optimizing the binding affinity of a carrier protein: a case study on the interaction between soluble IFNAR2 and interferon beta. J Biol Chem 2004;17:18046-18053. [PubMed: 14960565] 
Figure $1 \mathrm{~A}$

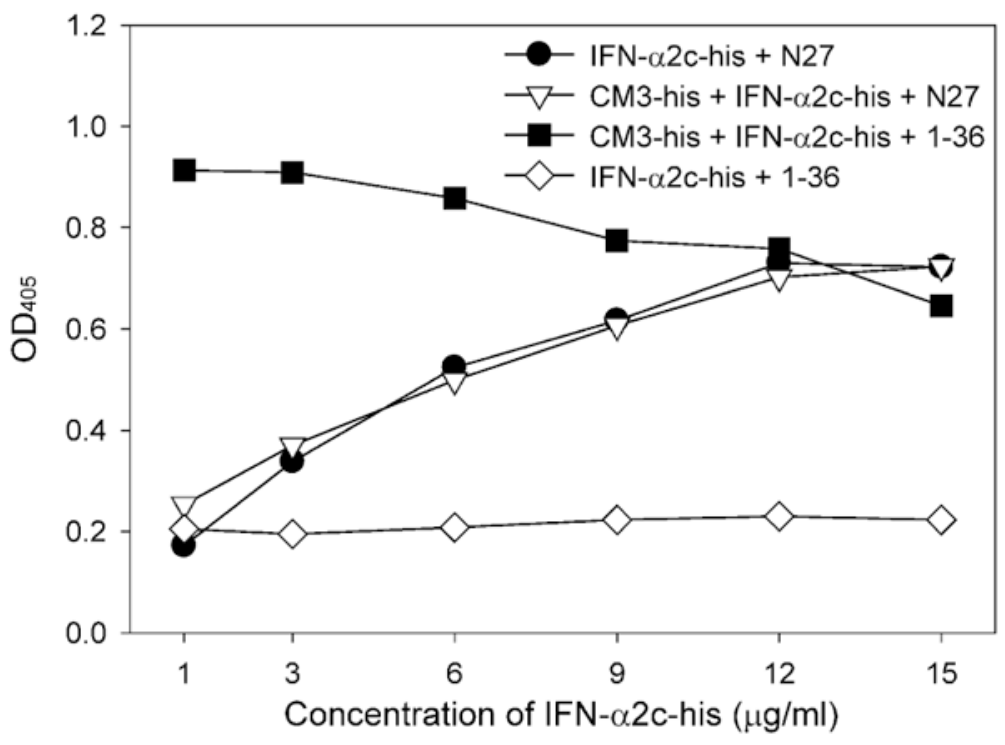

Figure 1.

Figure 1A. Reactivity of IFN- $\alpha 2 \mathrm{c}$ with IFNAR2-EC pre-incubated with CM3 $(150 \mu \mathrm{g} / \mathrm{ml})$ in competitive sandwich ELISA. Each data point represents the mean of three replicate assays (triplicates) from a representative experiment.

Figure 1B. Reactivity of CM3 with IFNAR2-EC pre-incubated with IFN- $\alpha 2 \mathrm{c}(15 \mu \mathrm{g} / \mathrm{ml})$ in competitive sandwich ELISA. Each data point represents the mean of three replicate assays (triplicates) from a representative experiment. 


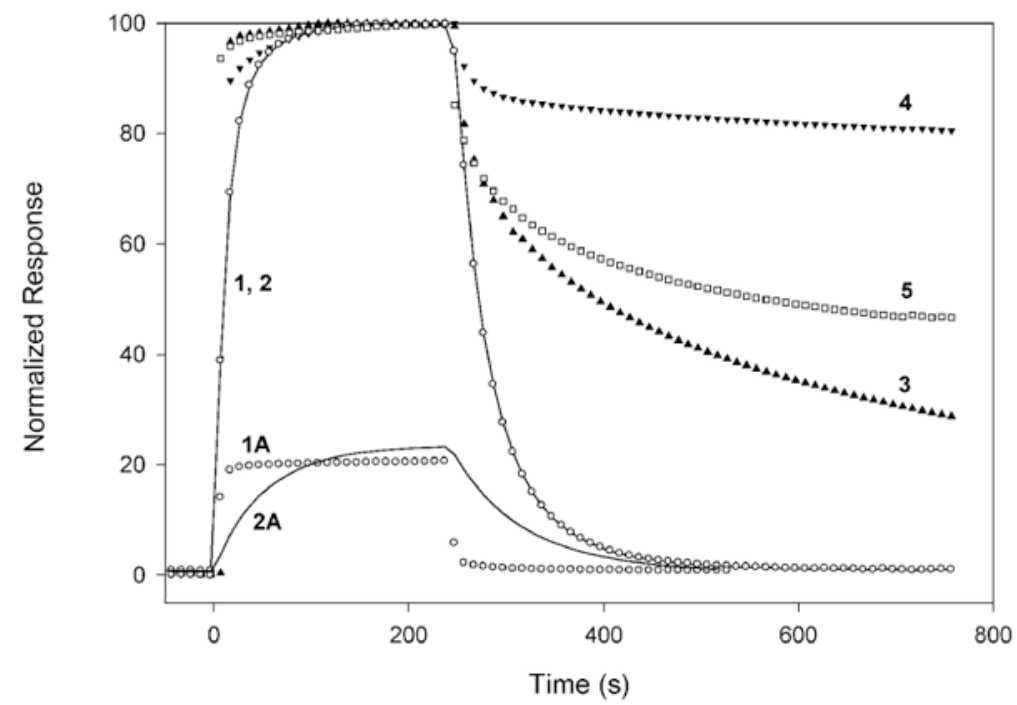

Figure 2.

Comparative binding of IFNAR2-EC to IFN- $\alpha 2 \mathrm{c}$ or $\mathrm{CM} 3$ immobilized on the chip surface and vice versa, measured by SPR. $700 \mathrm{nM}$ IFNAR2-EC in the absence or the presence of soluble IFN- $\alpha 2 c$ or CM3, respectively, were injected onto the chip surfaces to which 2700 RU IFN$\alpha 2 \mathrm{c}(1,1 \mathrm{~A}$, open circles) or $5900 \mathrm{RU}$ CM3 (2, 2A, solid line) were immobilized; $800 \mathrm{nM}$ IFN$\alpha 2 \mathrm{c}$ (3) or $800 \mathrm{nM} \mathrm{CM} 3$ (4) or their mixture (5) were injected onto the chip surfaces to which 1200,1345 RU and 1230 RU of IFNAR2-EC, respectively, were immobilized. Data were normalized to set the maximal response to 100 for comparative purpose, every $10^{\text {th }}$ point is shown. The $R_{\max }$ value (in RUs) was $~ 600$ (1), 1800 (2), 690 (3), 560 (4), and 530 (5), respectively. 


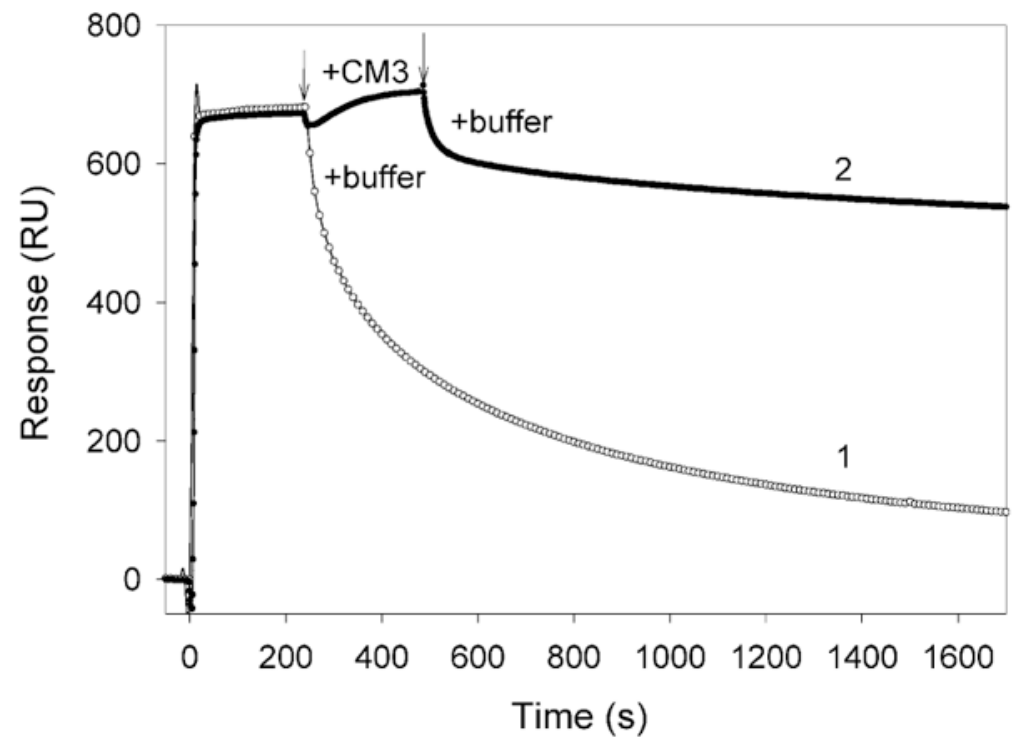

Figure 3.

Effect of CM3 on the interaction of IFN- $\alpha 2 \mathrm{c}$ with the immobilized IFNAR2-EC. $800 \mathrm{nM}$ IFN$\alpha 2 \mathrm{c}$ was injected onto the chip surfaces to which (1) $\sim 1200$ RU IFNAR2-EC or $(2) \sim 1300$ RU IFNAR2-EC were immobilized and allowed to dissociate in the absence (1) or presence of $800 \mathrm{nM} \mathrm{CM} 3$ (2). Arrows indicate injections of buffer or CM3. 


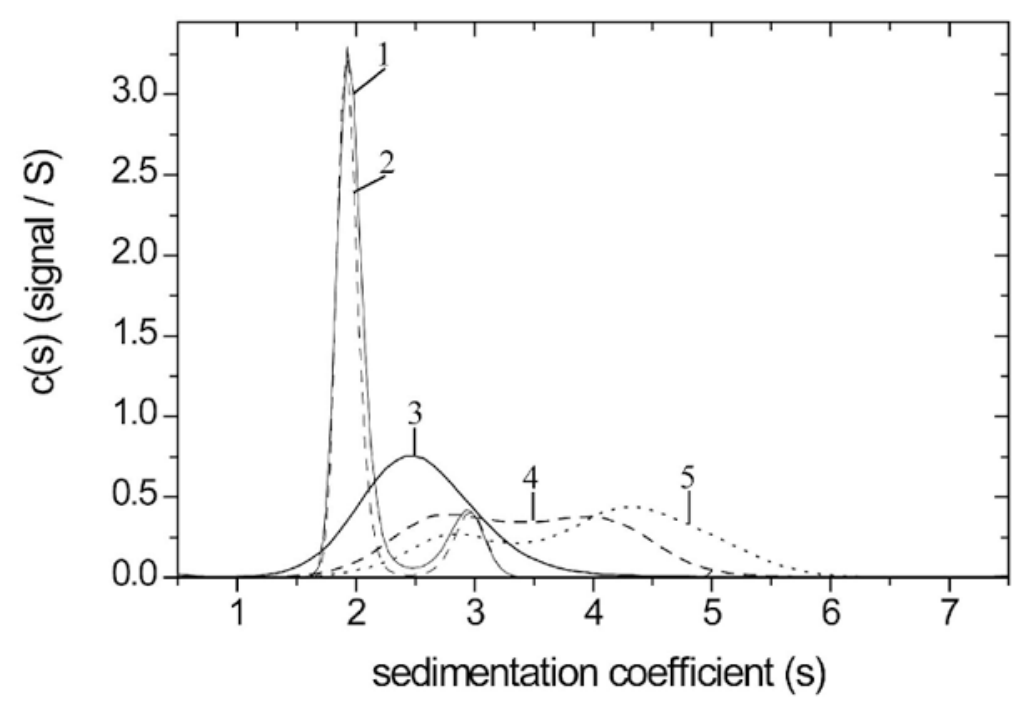

Figure 4.

Comparison of the sedimentation coefficient distributions for interferons IFN- $\alpha 2 \mathrm{c}$ and CM3. The c(s) distributions for CM3 at loading concentrations of $1.0 \mathrm{mg} / \mathrm{mL}$ (trace 1) and $0.5 \mathrm{mg} /$ $\mathrm{mL}$ (trace 2) exhibit a major peak at $1.94 \mathrm{~S}$ corresponding to CM3 monomer and small fraction of cross-linked dimer at $2.92 \mathrm{~S}$. The $\mathrm{c}(\mathrm{s})$ distribution for the IFN- $\alpha 2 \mathrm{c}$ mixtures at $0.1 \mathrm{mg} / \mathrm{mL}$ (trace 3), $0.4 \mathrm{mg} / \mathrm{mL}$ (trace 4 ) and $0.8 \mathrm{mg} / \mathrm{mL}$ (trace 5) exhibit a concentration-dependent increase in the weight-average sedimentation coefficient indicative of oligomerization. 

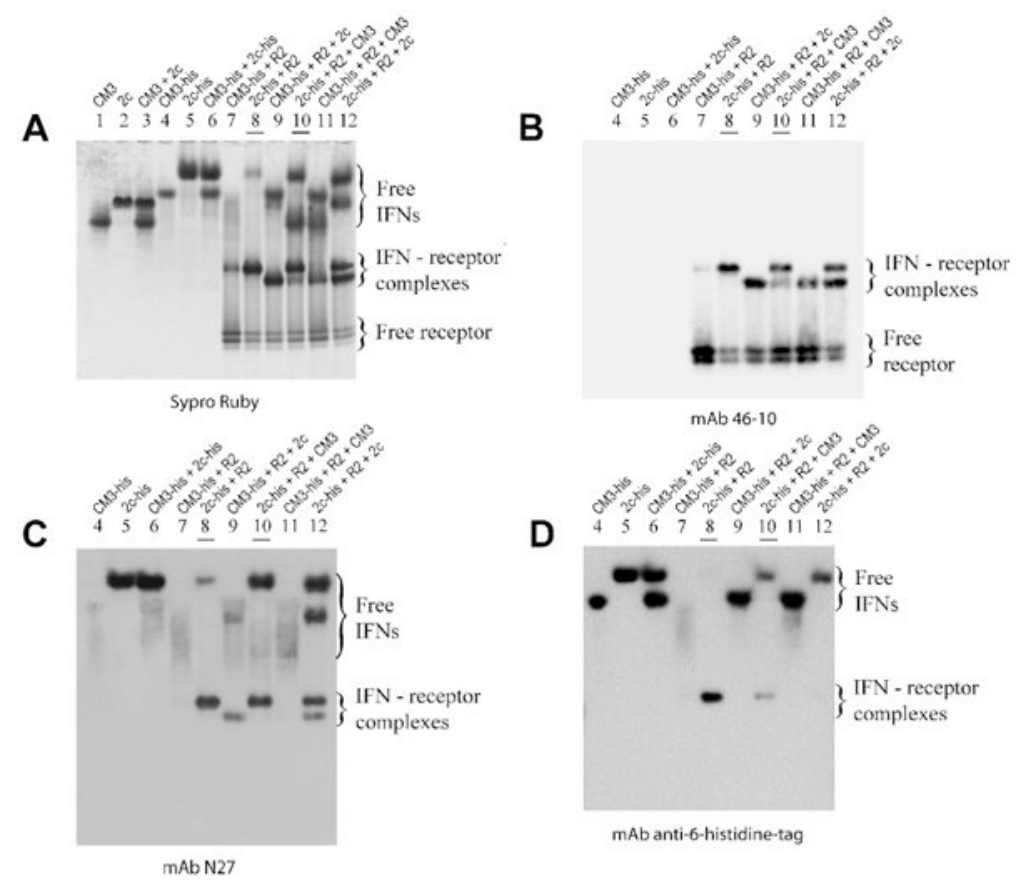

Figure 5.

Competitive bindings of IFN- $\alpha 2 \mathrm{c}$ and CM3 with IFNAR2-EC in (A) native electrophoresis (10\% Tris Glycine gel, stained with Sypro Ruby) and reactivity of mAbs: (B) 46.10, (C) N27, (D) anti-His-tag in immunoblot after native electrophoresis. IFNs $(0.05 \mathrm{nmol})$ were incubated with IFNAR2-EC $(0.04 \mathrm{nmol})$ at $37^{\circ} \mathrm{C}$ for 1 hour, at molar ratio 1.25:1:1.25 (lane 1 - CM3, lane 2 - IFN- $\alpha 2 c$, lane 3 CM3 + IFN- $\alpha 2 c$, lane 4 - CM-6-histidine-tag, lane 5 - IFN- $\alpha 2 c-6$ histidine-tag, lane 6 - CM3-6-histidine-tag + IFN- $\alpha 2 c-6$-histidine-tag, lane 7 - CM3-6histidine-tag + IFNAR2-EC, lane 8 - IFN- $\alpha 2 c-6$-histidine-tag + IFNAR2-EC, lane 9 - CM3-6histidine-tag + IFNAR2-EC + IFN- $\alpha 2 c$, lane 10 - IFN- $\alpha 2 c-6$-histidine-tag + IFNAR2-EC + CM3, lane 11 - CM3-6-histidine-tag + IFNAR2-EC + CM3, lane 12 - IFN- $\alpha 2 c-6$-histidine-tag + IFNAR2-EC + IFN- $\alpha 2 c$. 
Figure $6 \mathrm{~A}$

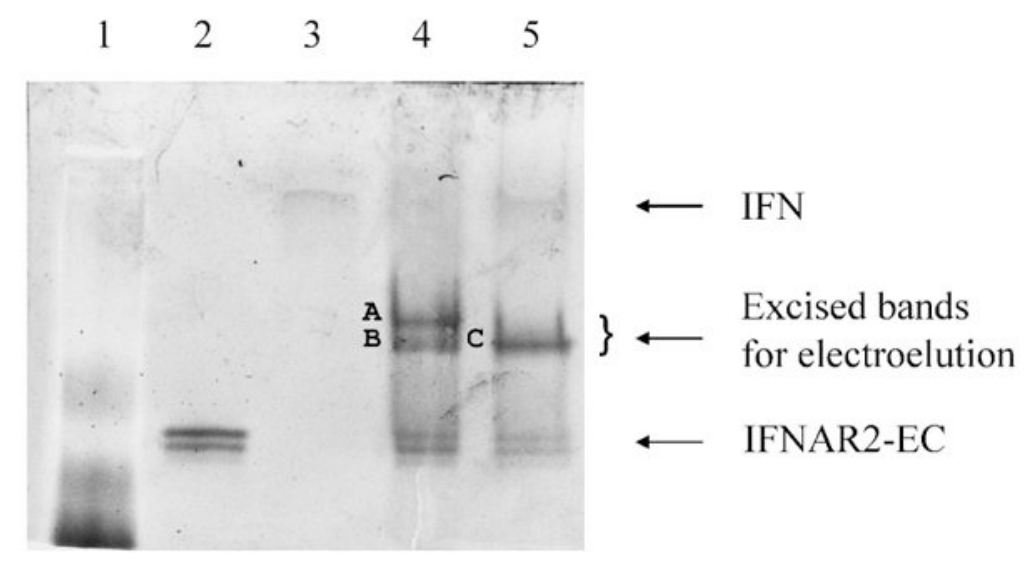

Figure 6.

Figure 6A. Native electrophoresis (10\% Tris Glycine gel, stained with Sypro Ruby) illustrated bands $(\mathrm{A}, \mathrm{B}, \mathrm{C})$ were excised for electroelution. IFNs were incubated with IFNAR2-EC at $37^{\circ}$ $\mathrm{C}$ for 1 hour at molar ratio 1.25:1:1.25 of IFN:IFNAR2-EC:IFN. Lane 1 - MW standard, lane 2 - IFNAR2-EC, lane 3 - IFN- $\alpha 2 c$, lane 4: bands A, B IFN- $\alpha 2 c-6$-histidine-tag + IFNAR2-EC + CM3, lane 5: bands C CM3-6-histidine-tag + IFNAR2-EC + IFN- $\alpha 2 c$.

Figure 6B. Analysis of electro-eluted samples in 10-20\% SDS Tris Glycine gel (stained with Sypro Ruby) under reducing conditions. Lane 1 - IFNAR2-EC (1 $\mu \mathrm{g})$, lane 2 - CM3-6-histidinetag $(1 \mu \mathrm{g})$, lane 3 - CM3 $(1 \mu \mathrm{g})$, lane 4 - IFN- $\alpha 2 \mathrm{c}-6$-histidine-tag $(1 \mu \mathrm{g})$, lane 5 - IFN- $\alpha 2 \mathrm{c}(1$ $\mu \mathrm{g}$ ), lane 6 - IFN- $\alpha 2 \mathrm{c}-6$-histidine-tag + IFNAR2-EC + CM3 (band A from native gel, Figure $6 \mathrm{~A}$ ), lane 7 - IFN- $\alpha 2 \mathrm{c}-6$-histidine-tag + IFNAR2-EC + CM3 (band B from native gel, Figure 6A), lane 8 - CM3-6-hisitidine-tag + IFNAR2-EC + IFN- $\alpha 2 \mathrm{c}$ (band C from native gel, Figure 6A). 


\section{IFN-alpha2c/IFN-alpha2c-his}

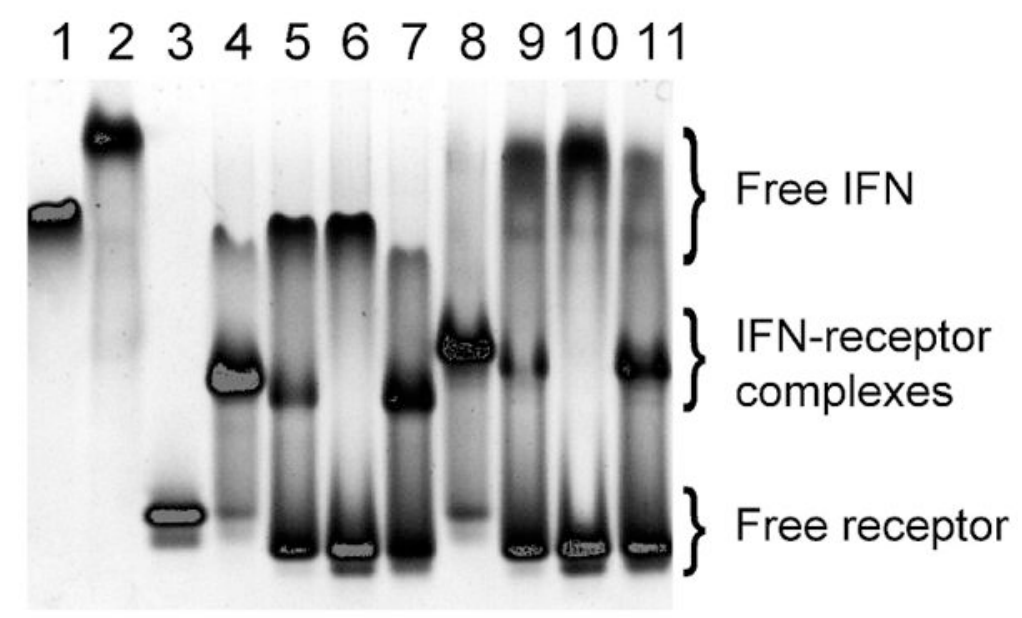

Figure 7.

Figure 7A. Binding of IFN- $\alpha 2 \mathrm{c}$ and IFN- $\alpha 2 \mathrm{c}-6$-histidine-tag with IFNAR2-EC mutants in native electrophoresis (10\% Tris Glycine gel, stained with Sypro Ruby). IFNs were incubated with IFNAR2-EC at $37^{\circ} \mathrm{C}$ for 1 hour at molar ratio 1.25: 1. lane 1 - IFN- $\alpha 2 \mathrm{c}$, lane 2 - IFN$\alpha 2 c-6$-histidine-tag, lane 3 - IFNAR2-EC, lane 4 - IFN- $\alpha 2 c$ + IFNAR2-EC, lane 5 - IFN- $\alpha 2 c$ + IFNAR2-EC I47A, lane 6 - IFN- $\alpha 2 c$ + IFNAR2-EC M48V, lane 7 - IFN- $\alpha 2 c$ + IFNAR2-EC I105A, lane 8 - IFN- $\alpha 2 c-6$-histidine-tag + IFNAR2-EC, lane 9 - IFN- $\alpha 2 c-6$-histidine-tag + IFNAR2-EC I47A, lane 10 - IFN- $\alpha 2 c-6$-histidine-tag + IFNAR2-EC M48V, lane 11 - IFNa2c-6-histidine-tag + IFNAR2-EC I105A.

Figure 7B. Bindings of CM3 and CM3-6-histidine-tag with IFNAR2-EC mutants in native electrophoresis (10\% Tris Glycine gel, stained with Sypro Ruby). IFNs were incubated with IFNAR2-EC at $37^{\circ} \mathrm{C}$ for 1 hour at molar ratio 1.25: 1. lane 1 - CM3, lane 2 - CM3-6-histidinetag, lane 3 - IFNAR2-EC, lane 4 - CM3 + IFNAR2-EC, lane 5 -CM3 + IFNAR2-EC I47A, lane 6 - CM3 + IFNAR2-EC M48V, lane 7 - CM3 + IFNAR2-EC I105A, lane 8 - CM3-6histidine-tag + IFNAR2-EC, lane 9 - CM3-6-histidine-tag + IFNAR2-EC I47A, lane 10 CM3-6-histidine-tag + IFNAR2-EC M48V, lane 11 - CM3-6-histidine-tag + IFNAR2-EC I105A. 
Table 1

Neutralization of antiproliferative (AP) activities of interferons with IFNAR2-EC on Daudi cells at 48 hour time point

\begin{tabular}{|c|c|c|}
\hline IFNs & AP(ng/ml) & AP(ng/ml) With IFNAR2-EC \\
\hline IFN- $\alpha 2 c$ & 0.03 & 0.1 \\
\hline $\mathrm{CM} 3$ & 0.4 & 1.4 \\
\hline IFN- $\alpha 2 \mathrm{c}+\mathrm{CM} 3$ & 0.04 & 0.4 \\
\hline
\end{tabular}

* Concentration that inhibits cell growth by $50 \%$. Daudi cells were mock-treated or treated with IFN- $\alpha 2 \mathrm{c}$, CM3, or their mixture (tenfold dilutions from initial concentrations of $360 \mathrm{ng} / \mathrm{ml}$ for single IFN, or equimolar IFN mixture) with or without IFNAR2-EC (at a constant concentration of $5 \mu \mathrm{g} / \mathrm{ml}$ ). Data shown are from one representative experiment. 